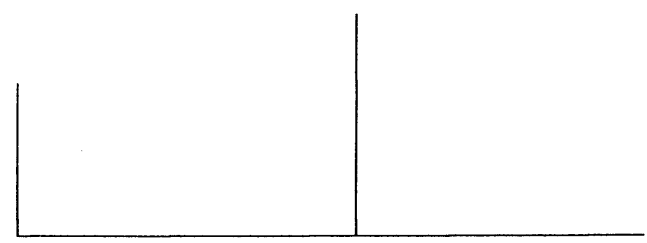

Rev. Latinoam. Psicopat. Fund., IV, 1, 182-186

Psicossomática: de Hipócrates à psicanálise

Rubens Marcelo Volich

São Paulo: Casa do Psicólogo, 2000

(Coleção Clínica Psicanalítica)

\title{
Psicossomática: de Hipócrates à psicanálise
}

\section{Patrícia Lacerda Bellodi}

Por que comigo? Por que agora? Por que desse modo?

Para quem cuida de pessoas que adoeceram (e ao cuidar, escuta...) questionamentos como esses não são incomuns.

Saber a resposta, uma resposta, saber o porquê.

Destino? Caminhos...

O livro Psicossomática: de Hipócrates à psicanálise, de Rubens Marcelo Volich, não apresenta respostas prontas e definitivas a essas questões tão difíceis e sofridas.

Apresenta sim, e vem disso seu grande valor, de forma clara, completa e didática, a todos aqueles que se interessam pelas relações corpo-mente - na doença e na saúde - que destino e caminhos tomaram, ao longo do tempo, essas perguntas que marcam o homem desde épocas "imemoriais"...

\section{O caminho histórico da compreensão do adoecer}

Em seu primeiro capítulo, o autor apresenta a evolução histórica das concepções sobre o adoecer. Mostra o homem - seja ele feiticeiro, sacerdote, filósofo ou cientista - procurando compreender os mistérios do funcionamento de seu corpo e a relação desse com aquilo que pode ser chamado de alma, espírito ou mente...

O papel dos curandeiros na Antiguidade convida a pensar nas escolhas atuais pela Medicina: uma raiz "histórica" na magia que ainda "encanta" 


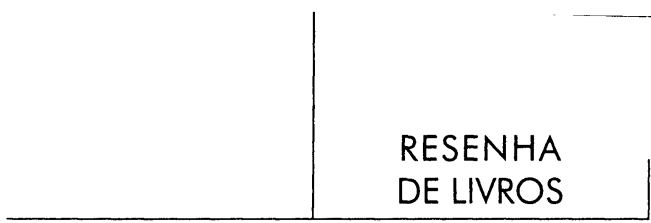

futuros médicos no presente... Outra raiz, a "mitológica", também convida a refletir sobre a busca de características "tanatolíticas" por muitos daqueles que a exercem. Esculápio mostra os perigos da onipotência na função terapêutica: morre também aquele que cuida, se não cuidar de seus próprios desejos...

Nada mais antigo e mais moderno do que Hipócrates e sua concepção do ato médico indissociado da parceria com o paciente: "é necessário que o médico ajude o doente a combater a doença”. O homem passa a ser visto como responsável por sua doença e, por isso mesmo, tendo uma história a contar para quem dele vai cuidar.

Preconiza Hipócrates que o cuidador deve necessariamente aliar ao conhecimento científico uma visão humanística. Modelo de médico este que, atualmente, faz escolas de medicina se preocuparem em incluir em seu currículo conteúdos de bases humanísticas! Mostra bem o autor, ao longo do capítulo, como as concepções de Hipócrates têm sido esquecidas e resgatadas em "ondas" através do tempo...

Sem dúvida, Descartes é apresentado como figura histórica fundamental (séc. XVII) ao instaurar a concepção dualista (cisão) entre corpo e alma. Reforçada depois pela física newtoniana (séc. XVIII), a doença passa a ser considerada como um fenômeno da Natureza passível de ser equacionado por meio de padrões objetivos. Entretanto, ao lado dos avanços científicos da biologia do séc. XIX (especialmente da patologia) a preocupação com o subjetivo e o individual também persistia. Empregando como recurso terapêutico o hipnotismo e a sugestão, Charcot, em Paris cuidava de suas pacientes histéricas com sintomas somáticos. E "esperava" Freud, sem "esperar", entretanto, a revolução de suas idéias - tema do capítulo seguinte.

\section{O caminho de Freud: da neurologia à clínica das neuroses}

Neste segundo capítulo, Volich relata o caminho de Freud de médico/pesquisador da neurologia à clínica das neuroses. Ao intuir que não havia correspondência entre os sintomas histéricos e a estrutura dos órgãos anatômicos, este desenvolve uma teoria, um método de investigação e uma clínica que passa a marcar a concepção das relações entre o psíquico e o somático de forma fundamental.

A psicanálise inaugura uma "anatomia imaginária" e coloca o inconsciente e a sexualidade como estruturantes do sujeito - sexualidade esta apoiada no corpo e na relação deste corpo com um outro humano significante. O próprio conceito de pulsão é, segundo Freud, um "conceito-limite" entre o somático e o psíquico e compreender os destinos e vicissitudes desta energia libidinal foi essencial para a compreensão do funcionamento psicossomático.

A noção de trauma, ou seja, de quantidades elevadas de excitação (derivadas de eventos reais ou imaginários) ante às quais os recursos do sujeito não dão conta, ajuda a compreender o adoecer e o papel do cuidador junto ao paciente na administração desse "excesso". Quem nunca observou pacientes "atordoados/trau- 


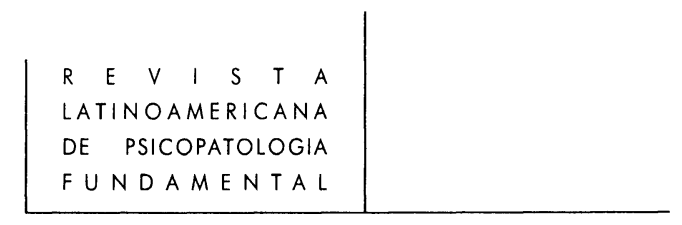

matizados" ao saber que estão gravemente doentes e a palavra do outro, médico, amigo ou familiar, auxiliando em sua continência e compreensão?

Também os polêmicos postulados de Freud a respeito da pulsão de vida e, especialmente, da pulsão de morte auxilia a pensar (compreender? aceitar?) "como alguém programado a usufruir a vida encaminha-se, às vezes precocemente, para a destruição de si mesmo e do outro". As dificuldades ante a aderência ao tratamento (quando as barreiras educacionais e sociais estão descartadas) talvez possam ser, com o auxílio deste conceito, menos (ou mais) difíceis de se tolerar pela equipe de saúde...

\section{O caminho da histeria de conversão às doenças orgânicas em geral}

No terceiro capítulo, o autor apresenta, então, as correntes modernas da psicossomática, originárias quase todas do modelo psicanalítico discutido nas páginas anteriores. Relata a história do interesse de alguns dos primeiros psicanalistas buscando compreender as diferentes doenças orgânicas e não mais apenas a histeria de conversão.

Ferenczi defende, já em 1926, a consideração das descobertas psicanalíticas no tratamento de toda e qualquer doença... Groddeck assinala que a expressão psicossomática remete não a um estado, mas à própria essência do ser humano. Mais uma vez Hipócrates é resgatado quando este último aponta que "não deveríamos esquecer que não é o médico que derrota a doença, mas o doente".

Outros psicanalistas também se destacam na "aventura psicossomática". Félix Deutsch e Franz Alexander buscando, na Escola de Psicossomática de Chicago, estabelecer relações entre estruturas de personalidade e tipos de doenças somáticas. Esforços esses que "marcaram" a psicossomática durante muito tempo com a idéia de especificidade. Os pioneiros da psicossomática no Brasil, como Perestrello, Capisano, José Fernandes Pontes e Miller de Paiva foram "alunos" aplicados da escola americana e poderiam estar, sem dúvida, presentes neste capítulo!

Por fim, também não são esquecidas pelo autor as contribuições fundamentais das vertentes psicofisiológicas com a noção de stress e a relação doença-depressão-imunidade dando origem às pesquisas em psiconeuroimunologia.

\section{A infância e o caminho da organização psicossomática}

Inicia o autor no quarto capítulo especificamente a discussão sobre a Psicossomática Psicanalítica. Um conceito-chave a ser desenvolvido neste capítulo é a idéia de que representar é fundamental para "metabolizar" estímulos e assim não adoecer... 


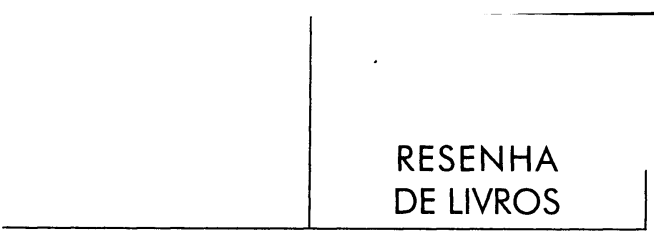

"Metabolização" essa que se inicia na infância quando a mãe busca proteger seu bebê contra estímulos, organiza seus comportamentos e interpreta suas reações. Fica claro o quanto os destinos da economia psicossomática dependem de uma "gerência materna" equilibrada: é apoiado nas lembranças das experiências de satisfação de suas necessidades pela mãe, que o bebê, ao repeti-las por meio da fantasia, inaugura sua vida psíquica.

Temos neste capítulo a apresentação das idéias fundamentais de Pierre Marty e do Instituto de Psicossomática de Pais quanto à relação entre a mentalização e a somatização.

A primeira tópica do aparelho psíquico é fundamental para essas idéias: o préconsciente, ao permitir a ligação do afeto a uma representação é fundamental para o equilíbrio psicossomático. Afeto livre ou desligado de representações é afeto que busca descarga por meio de comportamentos ou de funções somáticas e pode adoecer o sujeito.

$\mathrm{O}$ conceito de mentalização diz respeito à atividade do sonho, da fantasia e criatividade, operações de representação e simbolização por meio das quais o aparelho psíquico busca regular as energias pulsionais e instintivas. Se há falhas na constituição desse aparelho ou experiências de vida traumáticas e desorganizadoras, essas deficiências levam à utilização pelo organismo de recursos mais rudimentares como os motores ou os orgânicos.

Há na Psicossomática Psicanalítica a apresentação de uma proposta diagnóstica, prognóstica e terapêutica. Partindo de informações médicas e mentais, especialmente dos recursos de mentalização e do funcionamento do pré-consciente do paciente, este pode ser compreendido/diagnosticado em relação a quatro estruturas fundamentais: a neurose de caráter bem mentalizada, a de mentalização incerta, a mal mentalizada e a neurose de comportamento. Fica, entretanto, um pouco obscuro o lugar da psicose nesta proposta de classificação. É difícil compreender (aceitar?) o psicótico como um "indivíduo bem estruturado no plano mental...".

Mas, assinala Volich: é preciso evitar simplificações, pois é possível encontrarmos momentos de manifestações neuróticas e outros momentos somáticos no mesmo sujeito... Conclui o capítulo com uma colocação fundamental "a tentativa de privilegiar (o somático ou o ṕsíquico) é estranha tanto à natureza quanto à própria experiência do sujeito", e um desdobramento também fundamental: a necessidade de "um convite para uma verdadeira comunhão entre pesquisadores de diferentes campos do saber".

\section{Os caminhos do encontro terapêutico}

Virginie e a pasta folheada junto ao terapeuta/autor do livro: uma excelente maneira encontrada por Volich para discutir os desdobramentos terapêuticos da teoria descrita até esse momento do livro. 


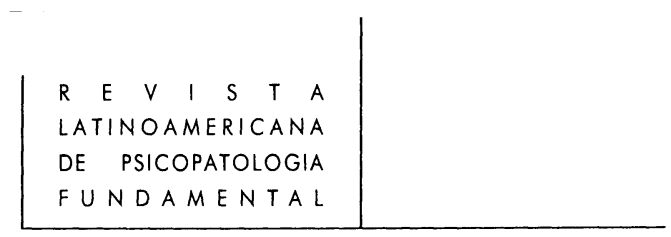

O relato consegue expressar o desafio do cuidar, difícil para o paciente e para o cuidador, pois resgata inevitavelmente a mais primordial e difícil experiência: sentirse desamparado e necessitar de um outro para sua superação...

Depender, confiar, acreditar, colaborar: tarefas difíceis para quem adoece.

Amparar, compreender, ser terapêutico: tarefas difíceis para quem escolhe cuidar.

Difíceis porque, bem mostra a psicanálise, são permeadas pela dimensão transferencial-contratransferencial, isto é, "contaminadas" por sentimentos, afetos, angústias, expectativas, nem sempre conscientes.

Destaca-se fundamentalmente a importante tarefa do terapeuta em propiciar recursos ao paciente que permitam pensar e elaborar o sofrimento. Um terapeuta que, como a mãe (já que o adoecer remete ao desamparo inicial da vida), protege o paciente temporariamente diante de situações difíceis de suportar: a doença-momento de vida ameaçada pela morte.

Mas, como bem aponta o autor, há vários obstáculos nesse caminho: resistências narcísicas inconscientes (tanto do médico quanto do psicanalista, desejando assumir isoladamente a tarefa de cuidar), a urgência dos sintomas orgânicos, as resistências do próprio paciente a um tratamento não médico, que pode ser representado como desvalorização de seu problema.

Trabalhar junto a esses obstáculos tem sido tarefa não apenas do psicólogo clínico que atua em instituições de saúde, mas também de médicos sensíveis ao sofrimento psíquico de seus pacientes (um dever ético, na verdade) e de profissionais de ambas as áreas dedicadas à psicologia médica e também (fundamental!) ao próprio ensino médico.

\section{Um caminho para o leitor, estrangeiro...}

Sem dúvida, ao final do livro, o leitor tem uma visão panorâmica e temporal das diferentes, históricas e atuais compreensões da relação mente-corpo. Consegue compreender bem a construção dos conceitos da Psicossomática Psicanalítica - cabe dizer, por meio de uma prévia e didática introdução da Psicanálise em si - e de suas propostas.

Mas, sugiro, especialmente, que volte este leitor ao trecho selecionado por Volich como epígrafe para seu livro.

Neste, "ouvimos" um médico, depois de refletir de forma angustiada sobre o saber e a impotência diante da morte, perguntar com raiva a um interlocutor "distante" e por isso "estrangeiro" (nós todos?):

"Compreendeis tudo isso? Vós compreendeis?". 